\title{
REVISTAMARACANAN
}

Seção Especial

\section{Alfredo Bosi: história, prosa, poesia e resistência}

\author{
Alfredo Bosï: history, prose, poetry and resistance
}

Haroldo Ceravolo Sereza*

Universidade Federal de São Carlos

São Carlos, São Paulo, Brasil

\begin{abstract}
* Professor convidado do programa de pós-graduação em Literatura da Universidade Federal de São Carlos. Doutor em Literatura Brasileira pela Faculdade de Filosofia, Letras e Ciências Humanas da Universidade de São Paulo.
\end{abstract}


No dia 7 de abril de 2021, Alfredo Bosi, aos 84 anos, tornou-se mais uma vítima da Covid19. Bosi era membro da Academia Brasileira de Letras e professor emérito da Faculdade de Filosofia, Letras e Ciências Humanas da Universidade de São Paulo, e sua morte durante esta pandemia, em que se combinam e potencializam brutalidades sanitárias, políticas e culturais, é mais um dos inúmeros episódios que nos tiraram o chão nos últimos tempos. Uma morte que representa tantas coisas que perdemos neste recente festival de derrotas contra as quais temos o dever, como intelectuais, de nos contrapor e resistir. Uso estas palavras não por acaso, mas como referência à própria obra de Bosi, em que a ideia de resistir e de se contrapor à ideologia dominante é recorrente e muitas vezes central.

Logo após concluir o curso de letras na Universidade de São Paulo, Bosi recebeu uma bolsa de estudos para estudar filosofia italiana na Faculdade de Letras de Florença, na Itália, para o ano letivo de 1961-1962. Voltando de lá, começou a dar aulas na USP como professor de italiano. De 1963 a 1970, escreveu regularmente no Suplemento Literário do jornal O Estado de S. Paulo, responsável pela seção "Letras Italianas". Em 1964, com uma tese sobre o itinerário narrativo de Luigi Pirandello, concluiu o doutorado. Em 1970, ano em que defende a tese de livre-docência Mito e poesia em Leopardi, deixou a literatura italiana, passou a dar aulas de literatura brasileira e lançou sua obra mais difundida, que marcou essa passagem: História concisa da literatura brasileira, escrita após ser indicado para a tarefa por José Paulo Paes.

Essa formação e tal trajetória profissional marcaram profundamente os trabalhos de Alfredo Bosi. Ainda que tenha havido muitos professores italianos na fundação da Universidade de São Paulo, nos anos 1930, e que a presença descendente de imigrantes italianos fosse bastante grande nas décadas iniciais da universidade, a influência da cultura e da universidade italianas foi sensivelmente menor do que a francesa no ensino superior paulista. Isso significou, para Bosi, o acesso e um conhecimento profundo não só de autores como Pirandello e Leopardi, mas também de pensadores como Giambattista Vico, Benedetto Croce e Antonio Gramsci de modo muito mais intenso que o de seus colegas. Ao mesmo tempo, era impossível manter-se no debate intelectual de ponta sem lidar com as outras tradições, sobretudo a francesa e a norteamericana.

Em maio de 2005, Bosi apresentou um depoimento biográfico num ciclo de conferências da Academia Brasileira de Letras. O título desse texto revela em boa medida como o próprio 
crítico via sua trajetória: "Caminhos entre a literatura e a história" (BOSI, 2005). ${ }^{1}$ No depoimento, ele afirma:

O que minhas teses me deixaram como legado intelectual, nesse fim dos anos 1960, era e é um problema agudo e fundamental. O problema da relação entre poesia e história, e, portanto, da relação entre o discurso da história literária e o da historiografia tomada na sua acepção ampla, que engloba a história social, a história econômica e a história política. ${ }^{2}$

Essa questão serve a Bosi para explicar o método adotado em História concisa da literatura brasileira. "Eu aderia intimamente à estética de Croce, que conferia uma identidade à poesia e à arte, em geral, como forma intuitiva, figural e expressiva de conhecimento [grifos do autor], mantendo, como vimos, uma distinção de fundo entre o ato poético e as outras práticas discursivas", relembra Bosi. ${ }^{3}$ "Mas a leitura de Gramsci e particularmente a resistência moral e cultural que marcara a mim e a minha geração ao longo dos anos de chumbo levaram-me a inserir decididamente o texto literário na trama da história ideológica em que fora concebido. Ambas as escolhas eram exigentes e faziam-se presentes na hora da escolha dos autores e no ajuizamento das obras." Tal oposição entre esses dois métodos leva o crítico a adotar um critério misto na análise dos textos que escolhe, defendendo, numa tentativa de síntese, que "um poema ou um romance podem ser significativos do ponto de vista sociológico ou político, mas essas duas qualidades não os elevam, por si mesmas, ao estatuto de obras de arte", para concluir que "as melhores obras de arte de todas as literaturas valem sempre pelos dois critérios, 0 representativo e o estético".

Ao adotar esses critérios, mais que capacidade, Bosi teve a necessidade de lidar com variadas tradições de forma erudita, didática e criativa, recorrendo a diferentes fontes do conhecimento (história, sociologia, filosofia e psicologia). Essa construção levou seus diferentes trabalhos a terem um alcance para além da área de letras, o que em Dialética da Colonização se descortinou completamente, num livro interessante para qualquer leitor disposto a pensar o país. Jaime Ginzburg, numa resenha que apresentava a tradução para o inglês de Dialética da Colonização, afirma que Bosi transformou o tema de seu livro num "objeto de estudo interdisciplinar", inserindo-o num debate que inclui intérpretes da trajetória social brasileira Sérgio Buarque de Holanda, com Raízes do Brasil, e Florestan Fernandes, com $A$ revolução burguesa no Brasil (outros, como Caio Prado Jr. e Raymundo Faoro, certamente seriam citados, não fosse o exíguo espaço da resenha). Ginzburg ainda chama a atenção para o fato de Bosi, nesta obra, dedicar boa parte do livro a estudos literários e assim demonstrar como elementos

\footnotetext{
${ }^{1}$ É interessante notar que esse depoimento retoma, sobretudo em seu início, quase literalmente (o que é explicitado pelo autor), o texto introdutório do livro Leitura de poesia (Ática, 1996), organizado por Bosi e que reúne textos de diversos críticos, com diferentes visadas em relação à poesia.

2 BOSI, Alfredo. "Caminhos entre a literatura e a história". Revista Estudos Avançados, n. 19 (55), p. 315334. São Paulo: IEA-USP, 2005, p.320.

${ }^{3}$ Ibidem, p.322.
} 
temáticos e formais presentes nas obras analisadas expressam conflitos coletivos em que indígenas e escravizados são alvos recorrentes de violência, desumanização e exclusão. ${ }^{4}$

Ainda que muitos outros intérpretes do Brasil recorram à produção literária como fonte em menor escala, Bosi realiza, neste trabalho, um movimento equilibrado em que história e literatura estão em diálogo permanente. Algo semelhante poderíamos dizer em relação a $O$ ser e o tempo da poesia, trocando a história pela filosofia. Os debates que conduziu sobre a obra de escritores como Graciliano Ramos, Raul Pompeia e Lima Barreto, presentes em Céu, Inferno (1988), Literatura e resistência (2002) e Ideologia e contraideologia (2010) (e nos livros monográficos sobre Machado de Assis, como Machado de Assis - o enigma do olhar, 1999), por sua vez, dialogam intensamente com a linhagem crítica que recorre à sociológica, que Bosi, como era de seu feitio, conheceu profundamente e jamais desconsiderou, embora a colocasse em perspectiva. Por fim, o casamento com Ecléa Bosi, ${ }^{5}$ que durou de 1961 até a morte da professora do Instituto de Psicologia da USP, em 2017, era uma parceria com trocas profundas, nem sempre explícitas, de lado a lado, o que significou para ele um forte conhecimento de fundo da psicologia social.

Em muitos sentidos, Bosi foi e não se importava em ser pensador minoritário: era socialista sem ser exatamente um marxista, o que o afastava de grande parte dos marxistas e dos liberais; era extremamente católico sem ser reacionário, o que o afastava dos grupos "conservadores". Via com bons olhos a influência do positivismo na política brasileira e no período getulista, quando a regra na Universidade de São Paulo era uma rejeição ao varguismo que unia direita e esquerda. Na crítica literária, recorreu à tradição não universitária de Augusto Meyer, Álvaro Lins, Lúcia Miguel Pereira e Otto Maria Carpeaux. Apenas para tomar um exemplo ilustrativo, são recorrentes e precisas suas citações a Marx, bem como a Antonio Gramsci, o que indica um interesse genuíno e respeitoso pela corrente marxista, sem que isso representasse uma filiação a ela.

Bosi travou uma forte polêmica em torno do liberalismo no século 19, num debate intenso com Roberto Schwarz e a interpretação da obra de Machado de Assis. Para Bosi, não cabe a qualificação de "ideias fora do lugar" para o liberalismo do século 19, tal como faz Schwarz em Ao vencedor as batatas (1977) e Um mestre na periferia do capitalismo (1990). Bosi, com profundo sentido histórico, argumentava, de modo geral, que o liberalismo e a escravidão não eram em si antagônicos e que a contradição entre ambos, notada por Schwarz, seria equivocada ou exagerada. Schwarz, por sua vez, diz não ter levado tão longe o argumento, e que a inadequação entre uma coisa e outra, que estaria representada na obra de Machado, é extremamente significativa, ainda que não seja absoluta. Essa polêmica ocupa, também, boa

\footnotetext{
${ }^{4}$ GINZBURG, Jaime. Review: Alfredo Bosi. Brazil and the Dialetic of Colonization. Brasiliana - Journal for Brazilian Studies. Vol. 5, n.1, p. 473, nov. 2016, p.473.

${ }^{5}$ Com quem teve dois filhos, Viviana Bosi (professora da Letras-USP) e José Alfredo Bosi, mestre em administração pela PUC-SP.
} 
parte de outra resenha de Dialética da Colonização, escrita por Schwarz, ainda em 1993. Num dos trechos desse texto, longo e detalhado, Schwarz afirma ser

indiscutível que o liberalismo econômico e a sua ênfase na propriedade podem calhar bem à defesa da escravidão. Neste sentido, conclui Bosi, trata-se de uma ideologia que, embora engendrada na Europa do século anterior, não introduz nada de "excêntrico, deslocado ou postiço" na linguagem de nossos políticos empenhados em legitimar o cativeiro. Ou seja, o que é funcional não é postiço, e vice-versa, o que à primeira vista parece plausível, mas pode não ser. ${ }^{6}$

Na mesma página, Schwarz segue argumentando e afirma que "a maioria dos exemplos lembrados por Bosi para provar a funcionalidade escravista do liberalismo serve igualmente para abonar a feição desconjuntada da mesma combinação". Schwarz, é importante registrar, atribui boa parte das conclusões de Bosi à adesão do crítico adversário nesta polêmica ao catolicismo (em sua vertente progressista).

A divergência entre ambos jamais foi superada. Pessoalmente, embora eu tenda a concordar mais com Schwarz em sua análise de Machado, considero impossível ignorar de todo a leitura de Bosi, que, por meio do passado colonial brasileiro, entre outros episódios, pega as contradições do liberalismo em seu nascedouro. Como não travei intimidade com Bosi, não posso medir o quanto polêmicas do gênero o afetavam pessoalmente. Mas, da leitura de seus textos, tenho a sensação de que, para ele, essas divergências intelectuais seriam assimiláveis e mesmo estimulantes. De um modo geral, podemos dizer que, no método crítico de Alfredo Bosi, não há teoria capaz de lidar completamente com qualquer problema, seja ele uma obra literária, seja ele a história de um país. Assim, as discordâncias, mais do que naturais, eram fundamentais para a construção do conhecimento amplo das formas artísticas e das interpretações históricas e políticas.

Numa obra ambiciosa, no melhor sentido da palavra, como a de Bosi, é difícil não encontrarmos pontos de desavença. $\mathrm{E}$, quando era necessário ser sintético, como ocorre em História concisa da literatura brasileira, nem sempre Bosi escapa da armadilha que mais o preocupava em relação ao historicismo: "Um dos resultados menos felizes do historicismo à outrance era e é, precisamente, o de subestimar a unicidade e a irrepetibilidade da obra de arte, na medida em que parte de categorias de estilo comuns a um certo período e tende a apagar as diferenças que estremam um texto e outro". ${ }^{7}$ Como estudioso do naturalismo em particular e dos realismos em geral, vejo Bosi pouco capaz de observar as nuances de um escritor antes complexo e sofisticado que irregular como Aluísio Azevedo, ${ }^{8}$ sobretudo no que tange ao desfecho de $O$ cortiço, em que se destaca o suicídio de Bertoleza, personagem central do romance; por

\footnotetext{
${ }^{6}$ SCHWARZ, Roberto. "Discutindo com Alfredo Bosi". Resenha de Dialética da colonização. Revista Novos Estudos, n. 36, p. 9-22. São Paulo: Cebrap, jul. 1993. Disponível em <http://novosestudos.com.br/produto/edicao-36/>. Acesso: 31 mai. 2021.

${ }^{7}$ Bosi, Alfredo. Op. cit, p. 323

${ }^{8}$ BOSI, Alfredo. História concisa da literatura brasileira, 3a. ed., 13a. tiragem. São Paulo: Cultrix, 1979, p. 209-214.
} 
outro lado, a síntese que faz da trajetória de Rachel de Queiroz ${ }^{9}$ é absolutamente precisa e admirável, sobretudo ao apontar a proximidade ideológica da escritora com o tenentismo: "verbalmente revolucionário em 30, sentimentalmente liberal e esquerdizante em face da ditadura, acabou, enfim, passada a guerra, identificando-se com a defesa passional das raízes do status quo". Ainda nesse capítulo dos incômodos, considero que, como ocorreu com outros críticos que adotam a nomenclatura, vejo como é problemático o uso que Bosi faz da categoria pré-modernismo para autores como Euclides da Cunha, Coelho Neto e Lima Barreto. Entendo que essa periodização sobrevaloriza 1922 e acaba ocultando a modernidade que, fora do Brasil, muitas vezes foi praticamente sinônimo do movimento naturalista, que antecedeu e marcou de diferentes formas a trajetória desses escritores.

Antes de encerrar, gostaria de fazer alguns registros pessoais sobre Bosi, embora não tenha tido muitos contatos com ele. Logo após a notícia de sua morte, o escritor José Roberto Torero publicou em sua página no Facebook uma crônica belíssima sobre como era ser aluno do professor na USP, com piparote ao final digno da mais alta literatura brasileira. Quem não quiser saber desse final, que pule este parágrafo, ou não reclame do spoiler. O Bosi de Torero era, naquele momento, o mais conhecido professor da Letras da Universidade São Paulo (Antonio Candido já estava, creio, aposentado), e sua entrada na classe era um evento: "Ele entra segurando só uma folha de papel, senta na sua cadeira, põe a folha na mesa à sua frente e começa a falar. Não escreve nada na lousa e não fica em pé, mas todos prestam atenção total, porque o raciocínio vai longe e rápido, mas sendo claro e preciso, fazendo um encadeamento perfeito". Segundo Torero, Bosi fazia citações bibliográficas sem recorrer a nenhum livro, segurando a folha de papel que, de vez em quando, olhava. "Esse cara é um craque nas anotações. Como consegue fazer todas essas informações caberem só numa folhinha? Será que escreve apenas umas palavras-chave? Será que usa ideogramas chineses? Letras microscópicas?", pergunta o aluno, que fica esperando, como todos os colegas, o final da aula para tentar decifrar o que havia de tão especial naquela folha de papel. E Bosi, ao fim da aula, deixa a sala e, sobre a mesa, fica a folha de papel. Dá-se uma corrida discreta dos alunos até a mesa e finalmente o segredo se mostra ao alcance das mãos. "Lembro que senti como se estivesse prestes a descobrir o grande mistério do Bosi", escreve Torero. "E descobri mesmo. A folha estava em branco". ${ }^{10}$

A folha em branco, longe de resolver (resolver não é descobrir, a escolha das palavras não é ingênua) o mistério, repõe o próprio mistério: o segredo de Bosi não estava na folha, mas sim na cabeça do próprio professor? Ou havia algo anotado nessa folha que milagrosamente se fez aula e desapareceu? A folha em branco é sinal de que a aula não fora preparada, demonstrando a extrema capacidade de articulação do raciocínio, ou que, por outra, estava tão

\footnotetext{
${ }^{9}$ Op. cit., p. 446-447.

${ }^{10}$ TORERO, José Roberto de. "Acho que foi a minha primeira aula com o Bosi". Post na rede social Facebook, 7 abr. 2021. Disponível em https://www.facebook.com/joserobertotorero/posts/1847705628729942. Acesso em 31 mai. 2021.
} 
preparada que não carecia de anotação nenhuma? Ou representa o sentimento de vazio de um aluno ideal, que não dá conta de tamanha erudição?

Também fui aluno de Bosi, provavelmente depois de Torero, numa turma de pósgraduação, como aluno especial, por volta de 2005 ou 2006. O curso era sobre Machado de Assis, e a leitura de Bosi sobre o escritor foi construída aula a aula, retomando de José Veríssimo e Sílvio Romero a Roberto Schwarz, a cuja obra dedicou uma aula inteira antes e rebatê-la, não sem antes passar por inúmeros críticos, entre os quais os já citados aqui Augusto Meyer e Lúcia Miguel Pereira. A impressão que eu tinha era de que o repertório estava resumido, após doze aulas semanais de quatro horas. A erudição era, portanto, notável, mas ela não se bastava: precisava sempre se articular com o que vinha antes e o que vinha depois. Talvez daí a sensação de que muita coisa ficara de fora, não por falta tempo, interesse ou conhecimento do professor, mas porque era desnecessária para o argumento central do curso.

Como não tinha obrigação, não apresentei o trabalho final, embora tenha chegado a discuti-lo com o professor, numa sessão de alguns minutos, que ele reservou para qualquer aluno que pedisse. Nesse momento, nem eu nem ele fizemos referência a dois encontros que tivemos antes, quando, como jornalista, o entrevistei duas vezes, para escrever sobre $O$ ser e $O$ tempo da poesia (em 2000, quando livro de 1977 foi relançado) e Literatura e resistência (2002).

A primeira conversa foi longa e bastante tensa para mim. Eu acabara de me tornar repórter do jornal O Estado de S. Paulo. Bosi, diretor do Instituto de Estudos Avançados da Universidade de São Paulo, estava no topo da lista dos intelectuais que me botavam medo, pela erudição e pela trajetória. Como repórter de cultura e crítico do jornal, entendia que o relançamento de $O$ ser e o tempo da poesia era uma pauta interessante e propus uma entrevista com o autor. Ela foi imediatamente aceita, mas eu não me sentia preparado para ela. Durante a conversa, que ocupou quase duas páginas do jornal (uma delas preenchida em grande parte por uma incrível caricatura de Loredano), Bosi foi, como depois entendi ser seu modo de agir, extremamente gentil, num diálogo respeitoso e didático, tentando traduzir questões complexas do debate estético presente na obra. Quando fui publicar a entrevista, ele pediu para lê-la e, assim, corrigir algumas imprecisões antes que chegasse aos assinantes e às bancas. Essa era uma decisão delicada, porque muita gente desiste do que falou aos jornalistas neste momento, e uma questão técnica e ética para os jornalistas: se ele fizesse isso, eu não teria como justificarme aos meus chefes. Abri a exceção dada a confiança de que ele não recorreria a esse expediente, e de fato não o fez: as alterações que pediu eram pequenos ajustes na transposição da oralidade para a escrita, sem mudar nada significativo as falas que passavam por Heidegger, Vico, Dante, Rainer Maria Rilke e diversos poetas brasileiros.

A segunda conversa, sobre Literatura e resistência, sumiu de minha memória, talvez pela naturalidade com que ocorreu, mas a registrei no jornal. O tema do livro e os autores tratados, como Basílio da Gama, Lima Barreto e Albert Camus, estavam mais próximos de minhas leituras e preocupações. Retomo, aqui, para finalizar, parte do que escrevi. Para Bosi, a boa literatura tem, em geral, uma dimensão contraideológica. Isso não significa, necessariamente, optar pelas 
boas causas. No texto do jornal, não sei se retirado do livro ou da conversa, eu concluí citando palavras do entrevistado e que, de alguma forma, creio, dialogam com os leitores de Maracanan: "A literatura acompanha a história, sim, mas os textos não são apenas reflexos da situação; são também, às vezes, uma profunda reflexão sobre o destino humano", disse Bosi. "Se Dante fosse só um cronista de Florença, não seria compreendido hoje, depois de 700 anos". 


\section{Referências}

BOSI, Alfredo. "Caminhos entre a literatura e a história". Revista Estudos Avançados, n. 19 (55), p. 315-334. São Paulo: IEA-USP, 2015.

BOSI, Alfredo. História concisa da literatura brasileira, 3a. ed., 13a. tiragem. São Paulo: Cultrix, 1979.

GINZBURG, Jaime. Review: Alfredo Bosi. Brazil and the Dialetic of Colonization. Brasiliana Journal for Brazilian Studies. Vol. 5, n.1, p. 473, nov. 2016.

SCHWARZ, Roberto. "Discutindo com Alfredo Bosi". Resenha de Dialética da colonização. Revista Novos Estudos, n. 36, p. 9-22. São Paulo: Cebrap, jul. 1993. Disponível em <http://novosestudos.com.br/produto/edicao-36/>. Acesso: 31 mai. 2021.

SEREZA, Haroldo Ceravolo. A arte de resistir. Jornal O Estado de S. Paulo, 29 set. 2002. Republicado por Opera Mundi em 7 abr. 2021. Disponível em <https://operamundi.uol.com.br/literatura/69242/a-arte-de-resistir-segundo-alfredo-bosi>. Acesso: 31 mai. 2021.

TORERO, José Roberto de. "Acho que foi a minha primeira aula com o Bosi". Post na rede social

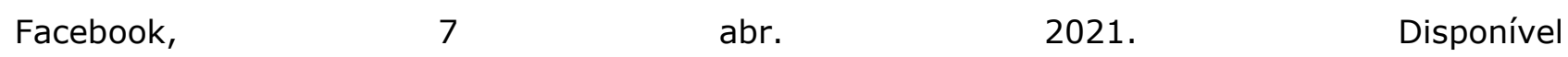
em https://www.facebook.com/joserobertotorero/posts/1847705628729942. Acesso em 31 mai. 2021. 